\title{
Strategi Peningkatan Kualitas Produk Lokal "Teh Sepang"Menggunakan Metode Quality Function Deployment (Qfd) Di Kabupaten Sumbawa
}

\author{
Rahmawati $^{1}$, Sumarlin ${ }^{1}$, Junaidi Efendi ${ }^{1}$ \\ ${ }^{1}$ Dosen Universitas Cordova \\ rahmawati.nur@gmail.com
}

\begin{abstract}
Teh Sepang' is a specialdrink of Sumbawanese people which included basic ingredient from Secang(Sepang)tree(CaesalpiniaSappan L). This research was aimed to know: attributes that becomecustomers' priority to choose the local product that is tehsepang'. Identifiedthe variablesof techniqueproduction had direct influence in improvement the quality of local product tehsepang'. Analysed how far the quality product performance in customer needs' and satisfaction. The method of this research wasdescriptive method, by using survey approach. This research was conducted in West Alas District, Sumbawa Regency. A technique of data collection was interview VOC (Voice of Customer) trough questioner. Technique of data sampling waspurposive sampling. The data in this research was analysed by using Quality Function Deployment (QFD).

Based on the result of analysed Importance to Customer showed that there were 10 first important level from the customers of tehsepang' that was; 1) The price appropriate with others attributes, 2) Man-power to produce tehsepang', 3) The ingredients influence the taste, 4) Products' Information, 5) Place of production, 6) Products' Image, 7) The ingredients influence aromatic8) Appropriate technology,9) Compatibility ingredients of production, 10) Contents' protection (its mean that the pack can use to safe the tea). Whilefrom 10 variables of technique production there were three variables which most influencetowardthe product quality increase that was; mix all of the ingredients into tea pouch, packaging into available tea boxes, and sort out the materials. While the highest customers'satisfaction performance at three sub product attributes included herbal tea with customer satisfaction performance level in the amount of 4.17, sub attribute of the new local product customers' satisfaction performance level in the amount of 4.57 and sub attribute of appropriate technology with customers' satisfaction performance level in the amount of 3.87 .
\end{abstract}

Keywords: Quality Increase, TehSepang', Importance to Customer, Quality Function Deployment 


\section{PENDAHULUAN}

Teh sepang' merupakan minuman khas masyarakat Sumbawa yang berbahan dasar serutan kayu secang (Caesalpinia Sappan L), Seperti teh lainnya teh sepang' memberikan manfaat bagi kesehatan tubuh manusia. Hal ini disebabkan oleh banyaknya kandungan senyawa kimia didalam tanaman secang seperti senyawa terpenoid, alkaloid, steroid, flavonoid, tannin, zat warna brazilin, dan asam galat (Kumala dan Muhamad, 2008).

Di Kabupaten Sumbawa produksi teh sepang' sudah ada sejak Juni 2015 lalu. Produsen mulai merintis usahanya dengan memproduksi sebanyak 50 kemasan dalam perhari oleh 4 orang tenaga kerja. Harga jual teh sepang' per kemasan sebesar Rp. $10.000,00,-$ standar penjualan ini ditetapkan karena teh sepang' termasuk minuman herbal yang dipercaya dapat memberikan kesegaran serta kesehatan karena fungsionalitas bahanbahan yang dikandungnya. Hal ini diperkuat oleh penelitian Munawaroh (2014), yang menyatakan bahwa fungsionalitas beberapa bahan dalam minuman wedang uwuh (berbahan dasar kayu secang) sehingga berkhasiat untuk kesehatan antara lain; menghangatkan badan, mengurangi kolestrol, menghilangkan rasa pegal dan capek, mengobati masuk angin, menyegarkan badan, serta memperlancar peredaran darah. Seiring dengan tetap berjalannya proses produksi sampai saat ini, membuktikan bahwa masyarakat memberikan respon positif terhadap keberadaan produk lokal teh sepang'.

Kelompok masyarakat pembuat teh sepang' masih memproduksi secara tradisional dengan teknologi yang sederhana. Tidak adanya konsistensi bahan-bahan yang digunakan dalam pembuatan teh sepang' membuat atribut-atribut yang melekat pada teh sepang' seperti rasa, warna dan aroma menjadi tidak konsisten, hal ini akan mempengaruhi tingkat kualitas produknya. Selain itu atributatribut lainnya seperti harga, ukuran, kebersihan, dan kemasan juga akan ikut berpengaruh dalam peningkatan kualitas produk teh sepang'. Belum adanya penelitian terhadap produk lokal teh sepang' membuat produsen teh sepang' belum mengetahui keinginan maupun harapan konsumen atas produknya.

Metode Quality Function Deployment (QFD) adalah suatu alat untuk mendesain dan mengembangkan produk baru yang mampu mengintegrasikan kualitas kedalam desain, memenuhi keinginan dan kebutuhan konsumen (customer needs and wants) yang diterjemahkan kedalam technical requirements. Beberapa peneliti sebelumnya yang menggunakana metode QFD dalam menerjemah suara pelanggannya diantaranya Elizabeth (2012), Joydeep et.al (2010).

Fenomena tersebut di atas menjadi penting untuk dikaji lebih lanjut. Sehingga pihak produsen maupun stakeholder harus bisa memilih strategi yang tepat dalam upaya menganalisis peningkatan kualitas produk lokal teh sepang' agar home industry teh sepang' tetap memiliki pertumbuhan (growth), kekuatan (strength), kemampuan bersaing (competitiveness), keuntungan (profitability) dan prospek (prosperity) secara berkelanjutan (sustainable).

Berdasarkan uraian di atas maka tujuan dalam penelitian ini yaitu:

1. Mengidentifikasi atribut-atribut yang menjadi prioritas konsumen dalam memilih produk lokal teh sepang'

2. Mengidentifikasi variabel teknis produksi yang berpengaruh langsung dalam peningkatan kualitas produk lokal teh sepang'.

3. Menganalisis sejauh mana kinerja kualitas produk lokal teh sepang' dalam pemenuhan kebutuhan dan kepuasan konsumen. 


\section{BAHAN DAN METODE}

\subsection{Lokasi Penelitian}

Lokasi penelitian dilakukan di Kecamatan Alas Barat, Kabupaten Sumbawa. Alasan dipilihnya daerah ini karena merupakan tempat sekelompok masyarakat yang secara ekonomi kurang produktif akan tetapi ingin berwirausaha dengan melakukan inovasi produk dengan membuat teh berbahan baku kayu secang (Caesalpinia Sappan L) yang banyak terdapat dilingkungan tempat tinggal mereka.

\subsection{Teknik Pengumpulan Data}

Teknik pengumpulan data pada penelitian menggunakan teknik survey. Data dikumpulkan dengan cara melakukan wawancara dengan menggunakan kuesioner terhadap konsumen responden sebanyak 30 orang yang ditentukan dengan teknik purposive sampling.

\subsection{Metode Analisis Data}

Untuk mengukur sejauh mana peningkatan kualitas dalam penelitian ini maka analisis dilakukan dengan pendekatan QFD (Quality Function Deplyment). Menurut Cohen (2007), metode Quality Function Deployment memiliki beberapa tahapan perencanaan dan pengembangan melalui matriks, sehingga dapat diketahui kebutuhan dan keinginan pelanggan yang menghasilkan usulan strategi prioritas untuk meningkatkan kualitas produk.

Untuk tahapan implemantasi metode Quality Function Deployment (QFD) dalam penelitian ini. Menurut Nasution (2006), ada tiga tahap yaitu: 1) tahap pengumpulan suara pelanggan (Voice Of Customer); 2) tahap penyusunan rumah kualitas (House of Quality) dan 3) tahap analisis dan interpretasi.

\subsubsection{Tahap pengumpulan suara pelanggan (Voice Of Customer),}

Pada tahap ini identifikasi elemenelemen VOC (Voice Of Customer). akan dilakukan survey dan melakukan wawancara langsung dengan konsumen responden untuk memperoleh suara pelanggan, melalui beberapa langkah sebagai berikut:

a.) Menentukan atribut-atribut produk teh sepang' sesuai dengan kebutuhan pelanggan (berupa data kualitatif);

b.) Mengukur atribut-atribut tersebut (berupa data kuantitatif).

c.) Membuat Diagram Afinitas. Dalam proses Quality Function Deployment (QFD) kebutuhan-kebutuhan pelanggan tersebut diatur dalam diagram afinitas. Diagram afinitas digunakan untuk mengumpulkan data, mengorganisasikan fakta, opini, dan ide, yang kemudian mengelompokkan elemen informasi tersebut sesuai dengan persamaan dan pertalian.

Diagram Afinitas digambarkan sebagai berikut:

\begin{tabular}{|c|c|c|}
\hline No & $\begin{array}{l}\text { Atribut } \\
\text { produk Teh } \\
\text { Sepang' } \\
\end{array}$ & $\begin{array}{l}\text { Konsekuensi / } \\
\text { kepentingan }\end{array}$ \\
\hline 1 & Harga & $\begin{array}{l}\text { Harga sesuai dengan } \\
\text { atribut lainnya } \\
\text { Produk termasuk teh } \\
\text { herbal } \\
\text { Teknologi tepat guna } \\
\text { Produk lokal baru }\end{array}$ \\
\hline 2 & Rasa & $\begin{array}{l}\text { Kesesuaian bahan- } \\
\text { bahan dalam produksi } \\
\text { teh sepang } \\
\text { Komposisi bahan- } \\
\text { bahannya } \\
\text { Cara pengolahan } \\
\text { bahan }\end{array}$ \\
\hline 3 & Warna & $\begin{array}{l}\text { Umur tanamana yang } \\
\text { disyaratkan dalam } \\
\text { berproduksi } \\
\text { Bagian tanaman yang } \\
\text { disyaratkan dalam } \\
\text { berproduksi }\end{array}$ \\
\hline 4 & Aroma & $\begin{array}{l}\text { Kesesuaian bahan- } \\
\text { bahan dalam produksi } \\
\text { teh sepang } \\
\text { Komposisi bahan- }\end{array}$ \\
\hline
\end{tabular}




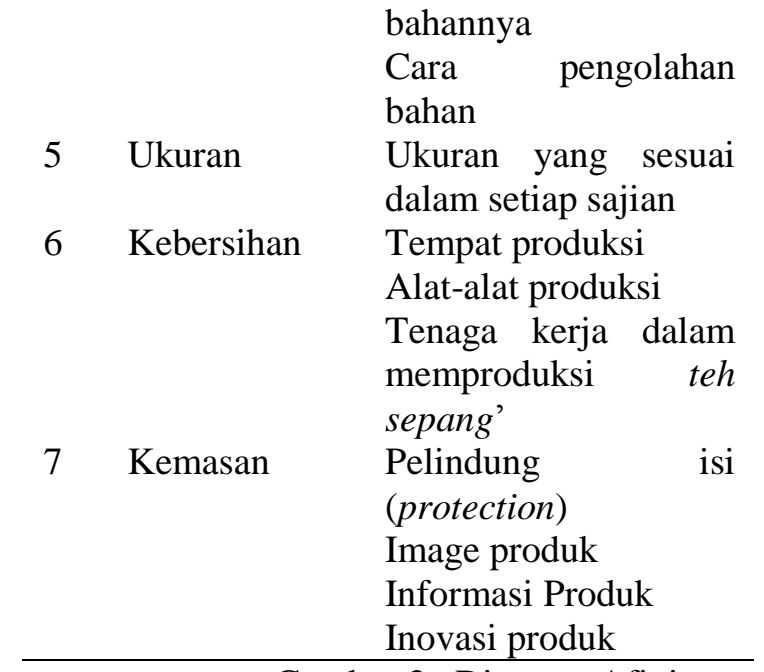

Gambar 3. Diagram Afinitas

d). Kuantifikasi data,

Setelah diagram afinitas dibuat, berikutnya mengkuantifikasikan data. Dalam tahap ini ada tiga data yang dibutuhkan yaitu; 1) kepentingan relative dari kebutuhan-kebutuhan pelanggan. 2) tingkat performasi kepuasan pelanggan untuk masing-masing kebutuhan. 3) tingkat kompetisi performansi kepuasan pelanggan untuk masing-masing kebutuhan.

Dari ketiga data diatas maka peneliti akan mencari informasi bagaimana customer melakukan prioritas. Sehingga ada tujuh tipe data yang dibutuhkan dalam mengkuantifikasi data antara lain:

1. Kepentingan Customer (Imfortance To Customer) Bagian ini berisikan hal-hal yang dipentingkan oleh pelanggan terhadap produk teh sepang', nilai ini merupakan rata-rata total keseluruhan nilai yang didapat dari setiap butir atribut dibagi dengan jumlah sampel, yang didapatkan dari sampling kepentingan.

2. Performansi Kepuasan Customer (Customer Satisfaction Performance). Nilai ini merupakan rata-rata total keseluruhan nilai yang didapat setiap butir dibagi dengan jumlah sampel, yang merupakan gambaran dari seberapa besar produk teh sepang' dalam memenuhi kebutuhan pelanggan.

3. Performansi Kepuasan Pesaing (Competitive Satisfaction Performance). Nilai ini merupakan rata-rata total keseluruhan nilai yang didapat setiap butir dibagi dengan jumlah sampel, yang merupakan gambaran dari sebarapa besar produk pesaing dalam memenuhi kebutuhan pelanggan.

4. Sasaran (Goal) yang ingin dicapai oleh tim rasio perbaikan ( Improvement Ratio). Goal merupakan Level Performance yang ingin dicapai home industry untuk memenuhi kebutuhan pelanggan (Customer Need). Performance Goal dinyatakan dalam skala numerik yang diperoleh dari nilai tertinggi perbandingan antara nilai kepentingan produk teh sepang nilai kepuasan teh sepang', dan nilai kepuasan produk pesaing.

5. Titik penjualan (Sales Point). Sales Point merupakan nilai kontribusi suatu kebutuhan konsumen terhadap daya jual produk teh sepang. Nilainya terbagi 3 dapat dilihat dalam tabel berikut:

\begin{tabular}{ll}
\multicolumn{2}{c}{ Tabel 1. Sales Point } \\
\hline \multicolumn{1}{c}{ Nilai } & \multicolumn{1}{c}{ Arti } \\
\hline 1 & Tidak ada titik jual \\
1,2 & Titik jual menengah \\
1,5 & Titik jual kuat \\
\hline
\end{tabular}

6. Pembobotan (Raw Weight);

Raw Weight merupakan suatu nilai yang menggambarkan tingkat kepentingan secara keseluruhan setiap kebutuhan pelanggan yang berdasarkan Importance to Customer dan Improvement Ratio. Nilai yang memiliki Raw Weight tinggi akan menjadi perhatian home industry untuk ditingkatkan dalam memenuhi kepuasan pelanggan.

7. Normalized Raw Weight

Normalized Raw Weight merupakan Raw Weight yang dinyatakan dalam persen atau pecahan antara 0 sampai 1 atau $100 \%$. 


\subsubsection{Tahap kedua adalah penyusunan House Of Quality (HOQ)}

Dalam gambar House Of Quality, terdapat 6 bagian yang menunjukkan urutan pengisian dari matrik perencanaan produk. Keenam bagian tersebut dapat dijelaskan sebagai berikut:

1. Bagian A (Customer Needs)

Pada bagian ini berisi informasi yang diambil dari diagram afinitas, yang merupakan data voice to customer, dan ditentukan tingkat kepentingan sub atribut.

2. Bagian B (Planning Matrik)

Pada bagian ini disebut sebagai tempat penentuan sasaran atau tujuan produk didasarkan pada interpretasi tim terhadap data riset pasar, Planning Matrik berisi informasi penting, antara lain: perhitungan satisfaction and competitive customer performance

3. Bagian C (Technical Response)

Pada bagian ini memuat informasi tentang gambaran produk yang akan dikembangkan, yang berasal dari Customer Needs. berupa gambaran proses produksi yang berasal dari informasi yang didapatkan dari produsesn teh sepang'. Informasi ini sebagai Substitute Quality Characteristic (SQC) yang mewakili suara pengembang.

4. Bagian D (Relationship)

Pada bagian ini adalah bagian terbesar matrik House of Quality dan menjadi bagian terbesar dari pekerjaan. Pada setiap sel dalam Relationship tim memberi nilai yang menunjukkan keberadaannya terhadap bagian C (Technical Response) dihubungkan dengan bagian A (Customer Needs). Nilai ini menunjukkan kepuasan pelanggan. Hubungan dinyatakan dengan simbol-simbol berikut:

Tabel 2. Relationship

\begin{tabular}{|c|c|c|}
\hline Simbol & Nilai & Arti \\
\hline & 0 & Tidak \\
\hline <kosong> & & hubungan \\
\hline \multirow{3}{*}{0} & 1 & Mungkin \\
\hline & & hubungan \\
\hline & 3 & Hubungan sedang \\
\hline \multicolumn{3}{|r|}{ 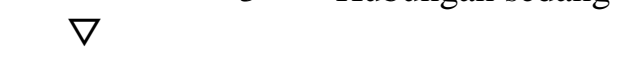 } \\
\hline - & 9 & $\begin{array}{l}\text { Hubungan sangat } \\
\text { kuat }\end{array}$ \\
\hline
\end{tabular}

\section{Bagian E (Technical Correlations)}

Bagian ini bentuknya seperti atap (roof), dan menunjukkan korelasi antara persyaratan teknis yang satu dengan yang lainnya dalam bagian C (Technical Response). Tanda yang digunakan adalah + (hubungannya positif), - (hubungannya negatif), dan kosong untuk 2 item yang tidak saling mempengaruhi.

6. Bagian F (Technical Matriks)

Bagian ini berisi beberapa jenis data yaitu: Technical Response Prioritas, urutan tingkat kepentingan persyaratan teknis, dan target Technical, target kinerja persyaratan teknis untuk produk baru atau teh sepang' yang akan dikembangkan.

\subsubsection{Tahapan ketiga adalah tahap analisa dan interpretasi.}

Dalam tahapan ini dilakukan analisis dan interpertasi terhadap House Of Quality (HOQ), yang sudah dibuat sebelumnya, sehingga dapat menentukan prioritas rekomendasi perbaikan sesuai kebutuhan konsumen.

Keenam bagian tersebut diatas dapat digambarkan House of Quality sebagai berikut:

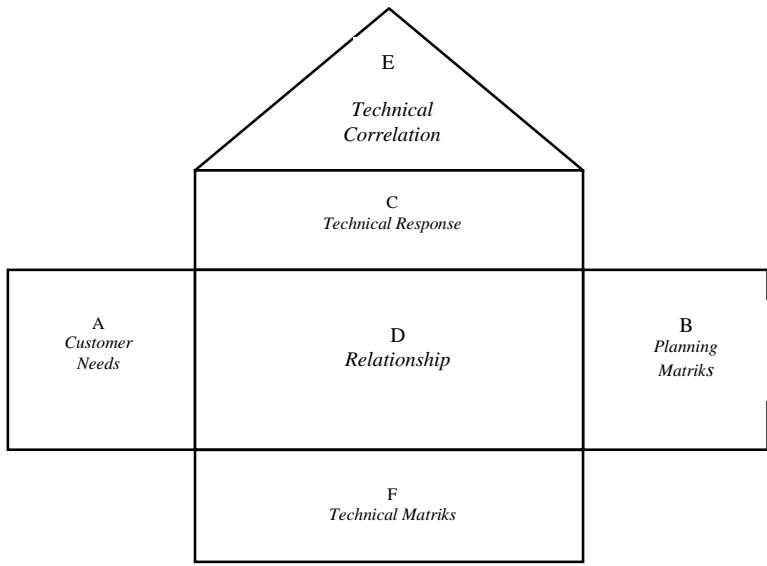

Gambar 4. House of Quality

Sumber: Nasution, (2006) 


\section{HASIL PENELITIAN DAN PEMBAHASAN}

\subsection{Tahap pengumpulan suara pelanggan (Voice Of Customer)}

Untuk penyusunan suara pelanggan, pertanyaan atau pernyataaan yang diajukan dalam kuesioner berdasarkan pada diagram afinitas yang telah disusun tim pengembang sebelumnya. Tahap selanjutnya adalah bagaimana konsumen melakukan prioritas terhadap atribut-atribut produk teh sepang dalam usahanya untuk meningkatkan kualitas produk, sehingga beberapa hal yang harus diukur antara lain; Kepentingan Customer (Importance To Customer), Performansi Kepuasan Customer (Customer Satisfaction Performance), Performansi Kepuasan Pesaing (Competitive Satisfaction Performance), Sasaran (Goal), Titik penjualan (Sales Point), Pembobotan (Raw Weight), dan Normalized Raw Weight.

\subsubsection{Kepentingan konsumen (Imfortance To Customer)}

Dari kuesioner yang disebarkan ke 30 responden maka Voice Of Customer diperoleh data customer need, yang merupakan urutan prioritas dalam peningkatan kualitas produk sesuai dengan kepentingan konsumen (Imfortance To Customer) Data tersebut terlihat dalam tabel dibawah ini:

Tabel 5. Imfortance to Customer

\begin{tabular}{cclcc|}
\hline No & $\begin{array}{c}\text { Atribut } \\
\text { teh } \\
\text { sepang }\end{array}$ & $\begin{array}{l}\text { Sub Atribut } \\
\text { produk teh } \\
\text { sepang }\end{array}$ & Bobot & Ranking \\
\hline 1 & Harga & $\begin{array}{l}\text { Harga sesuai } \\
\text { dengan }\end{array}$ & 2,03 & 1 \\
& & & \\
& atribut & & \\
& lainnya & 4,80 & 19 \\
& $\begin{array}{l}\text { Produk } \\
\text { termasuk teh } \\
\text { herbal } \\
\text { Teknologi } \\
\text { tepat guna }\end{array}$ & & \\
& & & \\
& &
\end{tabular}

Produk lokal

4,07

18

baru

2 Rasa

Kesesuaian

3,27

9

bahan-bahan

dalam

produksi teh

sepang

Komposis

2,13

3

bahan-

bahannya

Cara

pengolahan

bahan

3 Warna

Umur

tanaman

yang

disyaratkan

dalam

berproduksi

Bagian

$3,80 \quad 14$

tanaman

yang

disyaratkan

dalam

berproduksi

4 Aroma

Kesesuaian

3,37

12

bahan-bahan

dalam

produksi teh

sepang

Komposisi

3,17

7

bahan-

bahannya

Cara

$3,90 \quad 16$

pengolahan

bahan

Ukuran

Ukuran yang

sesuai dalam

3,57

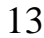

setiap sajian

Kebersihan

Tempat

2,90

5

produksi

Alat-alat

produksi

3,87

15

Tenaga kerja

2,10

2 


\begin{tabular}{|c|c|c|c|}
\hline \multirow{6}{*}{ Kemasan } & teh sepang' & & \\
\hline & $\begin{array}{l}\text { Pelindung isi } \\
\text { (protection) }\end{array}$ & 3,30 & 10 \\
\hline & $\begin{array}{l}\text { Image } \\
\text { produk }\end{array}$ & 2,93 & 6 \\
\hline & Informasi & 2,20 & 4 \\
\hline & Produk & & \\
\hline & $\begin{array}{l}\text { Inovasi } \\
\text { produk }\end{array}$ & 4,03 & 17 \\
\hline
\end{tabular}

Berdasarkan hasil analisis pada tabel 5 diatas menunjukkan bahwa nilai terendah yang secara berurutan satu sampai lima masingmasing adalah harga sesuai dengan atribut lainnya, tenaga kerja dalam memproduksi teh sepang, komposisi bahan-bahannya, informasi produk, tempat produksi, menunjukkan urutan prioritas yang menjadi perhatian pengembang atau produsen dalam upaya meningkatkan kualitas produk teh sepang'.

\subsubsection{Customer and Competitive Satisfaction Performance}

Nilai ini bertujuan untuk mengetahui seberapa puas responden terhadap atribut produk teh sepang' dan teh sariwangi sebagai pembandingnya. Alasan dipilihnya teh sariwangi sebagai pembandingnya karena pada saat penyebaran kuesioner konsumen lebih banyak mengkonsumsi teh sariwangi dibanding jenis teh lainnya.

Tabel 6. Customer and Competitive Satisfaction Performance

\begin{tabular}{cccc}
\hline No & $\begin{array}{c}\text { Sub Atribut } \\
\text { produk teh } \\
\text { sepang }\end{array}$ & $\begin{array}{c}\text { Customer } \\
\text { Satisfaction } \\
\text { Performance } \\
\text { Teh sepang' }\end{array}$ & $\begin{array}{c}\text { Competitive } \\
\text { Satisfaction } \\
\text { Performance } \\
\text { teh } \\
\text { sariwangi }\end{array}$ \\
\hline 1 & $\begin{array}{l}\text { Harga sesuai } \\
\text { dengan } \\
\text { atribut }\end{array}$ & 2,03 & 3,90 \\
& $\begin{array}{l}\text { lainnya } \\
\text { Produk } \\
\text { termasuk teh } \\
\text { herbal }\end{array}$ & 4,17 & \\
& & 1,50 \\
& & \\
& & \\
\end{tabular}

3

6

7

9

9

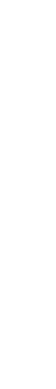

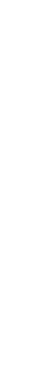




\begin{tabular}{rlrl} 
& $\begin{array}{l}\text { dalam } \\
\text { memproduksi } \\
\text { teh sepang' }\end{array}$ & & \\
17 & $\begin{array}{l}\text { Pelindung isi } \\
\text { (protection) }\end{array}$ & 2,77 & 5,00 \\
18 & $\begin{array}{l}\text { Image } \\
\text { produk }\end{array}$ & 2,63 & 5,00 \\
19 & $\begin{array}{l}\text { Informasi } \\
\text { Produk }\end{array}$ & 1,90 & 5,00 \\
20 & $\begin{array}{l}\text { Inovasi } \\
\text { produk }\end{array}$ & 4,43 & 4,00 \\
\hline
\end{tabular}

Berdasarkan analisis dari tabel 6 menunjukkan bahwa terdapat tiga sub atribut yang menjadi nilai kepuasan konsumen produk teh sepang' bila dibandingkan dengan teh sariwangi adalah pertama sub atribut produk termasuk teh herbal dengan tingkat kepuasan konsumen sebesar 4, 17, kedua sub atribut produk lokal baru dengan tingkat kepuasan konsumen sebesar 4,57, dan ketiga sub atribut teknologi tepat guna dengan tingkat kepuasan konsumen sebesar 3,87. Dari keempat sub atribut tersebut menunjukkan bahwa ada respon positif terhadap keberadaan produk teh sepang' sampai saat ini.

\subsubsection{Sasaran (Goal)}

Merupakan Level Performance yang ingin dicapai home industry untuk memenuhi kebutuhan pelanggan. Performance Goal ini dinyatakan dalam skala numerik yang tertinggi dari perbandingan Importance To Customer, Customer Satisfaction Performance and Competitive Satisfaction Performance. Seperti ditunjukkan dalam tabel berikut:

Tabel 7. Sasaran (Goal),

\begin{tabular}{llc}
\hline No & Sub Atribut produk teh sepang & Goal \\
\hline 1 & $\begin{array}{l}\text { Harga sesuai dengan atribut } \\
\text { lainnya }\end{array}$ & 3,90 \\
2 & Produk termasuk teh herbal & 4,80 \\
3 & Teknologi tepat guna & 3,87 \\
4 & Produk lokal baru & 4,57 \\
5 & Kesesuaian bahan-bahan dalam & 3,67 \\
& produksi teh sepang &
\end{tabular}

\begin{tabular}{cll}
6 & Komposisi bahan-bahannya & 4,17 \\
7 & Cara pengolahan bahan & 4,17 \\
8 & $\begin{array}{l}\text { Umur tanaman yang disyaratkan } \\
\text { dalam berproduksi }\end{array}$ & 4,33 \\
9 & $\begin{array}{l}\text { Bagian tanaman yang } \\
\text { disyaratkan dalam berproduksi }\end{array}$ & 4,33 \\
10 & $\begin{array}{l}\text { Kesesuaian bahan-bahan dalam } \\
\text { produksi teh sepang }\end{array}$ & 4,17 \\
11 & Komposisi bahan-bahannya & 4,33 \\
12 & Cara pengolahan bahan & 4,33 \\
13 & Ukuran yang sesuai dalam & 4,33 \\
14 & setiap sajian & 4,03 \\
15 & Tempat produksi & 4,00 \\
16 & Alat-alat produksi & 4,00 \\
17 & Tenaga kerja dalam & Pelindung isi (protection) \\
18 & Image produk & 5,00 \\
19 & Informasi Produk & 5,00 \\
20 & Inovasi produk & 5,00 \\
\hline
\end{tabular}

\subsubsection{Importance Ratio}

Nilai ini menunjukkan bobot kesulitan untuk melakukan peningkatan dalam memenuhi kebutuhan pelanggan. Nilai Importance Ratio diperoleh dari nilai perbandingan antara Goal dan Customer Satisfaction Performance.

Tabel 8. Importance Ratio

\begin{tabular}{llc}
\hline No & $\begin{array}{c}\text { Sub Atribut produk } \\
\text { teh sepang }\end{array}$ & $\begin{array}{c}\text { Importance } \\
\text { Ratio }\end{array}$ \\
\hline 1 & $\begin{array}{l}\text { Harga sesuai dengan } \\
\text { atribut lainnya }\end{array}$ & 1,92 \\
2 & $\begin{array}{l}\text { Produk termasuk teh } \\
\text { herbal }\end{array}$ & 1,15 \\
3 & $\begin{array}{l}\text { Teknologi tepat guna } \\
4\end{array}$ & 1 \\
5 & $\begin{array}{l}\text { Produk lokal baru } \\
\text { Kesesuaian bahan- } \\
\text { bahan dalam produksi }\end{array}$ & 1 \\
&
\end{tabular}




\begin{tabular}{|c|c|c|}
\hline & teh sepang & \\
\hline 6 & $\begin{array}{l}\text { Komposisi bahan- } \\
\text { bahannya }\end{array}$ & 2,36 \\
\hline 7 & Cara pengolahan bahan & 1,23 \\
\hline 8 & $\begin{array}{l}\text { Umur tanaman yang } \\
\text { disyaratkan dalam } \\
\text { berproduksi }\end{array}$ & 1 \\
\hline 9 & $\begin{array}{l}\text { Bagian tanaman yang } \\
\text { disyaratkan dalam } \\
\text { berproduksi }\end{array}$ & 1,09 \\
\hline 10 & $\begin{array}{l}\text { Kesesuaian bahan- } \\
\text { bahan dalam produksi } \\
\text { teh sepang }\end{array}$ & 1,13 \\
\hline 11 & $\begin{array}{l}\text { Komposisi bahan- } \\
\text { bahannya }\end{array}$ & 2,37 \\
\hline 12 & Cara pengolahan bahan & 1,04 \\
\hline 13 & $\begin{array}{l}\text { Ukuran yang sesuai } \\
\text { dalam setiap sajian }\end{array}$ & 1,08 \\
\hline 14 & Tempat produksi & 1 \\
\hline 15 & Alat-alat produksi & 1,14 \\
\hline 16 & $\begin{array}{l}\text { Tenaga kerja dalam } \\
\text { memproduksi teh } \\
\text { sepang' }\end{array}$ & 2,00 \\
\hline 17 & $\begin{array}{l}\text { Pelindung isi } \\
\text { (protection) }\end{array}$ & 1,81 \\
\hline 18 & Image produk & 1,90 \\
\hline 19 & Informasi Produk & 2,63 \\
\hline 20 & Inovasi produk & 0,90 \\
\hline
\end{tabular}

Berdasarkan analisis dalam tabel 8 menunjukkan sub atribut komposisi bahanbahannya (atribut rasa) dan komposisi bahanbahannya (atribut aroma) serta informasi produk (atribut kemasan) ketiga atribut tersebut merupakan atribut yang memiliki tingkat kesulitan terbesar dalam meningkatkan kualitas produk teh sepang'. Sehingga untuk atribut rasa dan aroma produsen harus mengupayakan tindakan lebih lanjut misalnya sebelum penentuan komposisi bahan dilakukan uji olganoliplik pada kedua atribut tersebut. dan untuk atribut kemasan harus bisa memuat informasi produk baik berupa manfaat produk ataupun diskripsi produk tersebut secara umum.

\subsubsection{Titik penjualan (Sales Point)}

Sales Point merupakan kemampuan menjual produsen teh sepang'. Dari hasil wawancara dengan pihak produsen teh sepang'. Berdasarkan data pada tabel 9 dibawah ini menunjukkan bahwa kemampuan menjual produk produsen teh sepang' berada rata-rata pada titik jual menengah $(1,2)$. sedangkan pada atribut harga terlihat sub atribut produk termasuk teh herbal, teknologi tepat guna, serta produk lokal baru, memberikan tingkat penjualan produk kuat $(1,5)$, hal ini menunjukkan bahwa produk teh sepang' bisa mamasuki pasar sasaran dengan memanfaatkan persepsi konsumen terhadap produk lokal yang bersifat herbal.

Tabel 9. Sales Point

\begin{tabular}{llc}
\hline No & $\begin{array}{l}\text { Sub Atribut produk } \\
\text { teh sepang }\end{array}$ & $\begin{array}{l}\text { Sales } \\
\text { Point }\end{array}$ \\
\hline 1 & $\begin{array}{l}\text { Harga sesuai dengan } \\
\text { atribut lainnya }\end{array}$ & 1,2 \\
2 & $\begin{array}{l}\text { Produk termasuk teh } \\
\text { herbal }\end{array}$ & 1,5 \\
3 & $\begin{array}{l}\text { Teknologi tepat guna } \\
4\end{array}$ & 1,5 \\
5 & $\begin{array}{l}\text { Produk lokal baru } \\
\text { Kesesuaian bahan- } \\
\text { bahan dalam produksi } \\
\text { teh sepang }\end{array}$ & 1,5 \\
6 & $\begin{array}{l}\text { Komposisi bahan- } \\
\text { bahannya }\end{array}$ & 1,2 \\
7 & $\begin{array}{l}\text { Cara pengolahan } \\
\text { bahan }\end{array}$ & 1,2 \\
8 & $\begin{array}{l}\text { Umur tanaman yang } \\
\text { disyaratkan dalam } \\
\text { berproduksi }\end{array}$ & 1,2 \\
9 & $\begin{array}{l}\text { Bagian tanaman yang } \\
\text { disyaratkan dalam } \\
\text { berproduksi }\end{array}$ & 1,2 \\
10 & $\begin{array}{l}\text { Kesesuaian bahan- } \\
\text { bahan dalam produksi }\end{array}$ & 1,2 \\
& $\quad 1,2$
\end{tabular}


teh sepang

\section{1}

Komposisi bahan-

bahannya

12 Cara pengolahan bahan

13 Ukuran yang sesuai dalam setiap sajian

14 Tempat produksi

15 Alat-alat produksi

16 Tenaga kerja dalam memproduksi teh sepang'

17 Pelindung isi (protection)

18 Image produk

19 Informasi Produk

20 Inovasi produk
1,2

1,2

1,2

\subsubsection{Pembobotan (Raw Weight) dan}

\section{Normalized Raw Weight}

Hasil kali Importance Rating, Sales Point dan Improvement Ratio adalah nilai Raw Weight. Nilai yang memiliki Raw Weight tinggi akan menjadi perhatian utama home industry teh sepang' untuk ditingkatkan dalam memenuhi kepuasan pelanggan.

Tabel 10. Raw Weight and Normalized Raw Weight

\begin{tabular}{|c|c|c|c|}
\hline No & $\begin{array}{c}\text { Sub Atribut } \\
\text { produk teh } \\
\text { sepang }\end{array}$ & $\begin{array}{c}\text { Raw } \\
\text { weight }\end{array}$ & $\begin{array}{c}\text { Normalized } \\
\text { Raw } \\
\text { Weight }\end{array}$ \\
\hline 1 & $\begin{array}{l}\text { Harga sesuai } \\
\text { dengan } \\
\text { atribut } \\
\text { lainnya }\end{array}$ & 4,68 & 0,05 \\
\hline 2 & $\begin{array}{l}\text { Produk } \\
\text { termasuk teh } \\
\text { herbal }\end{array}$ & 8,28 & 0,08 \\
\hline
\end{tabular}

3 Teknologi $\quad 4,80 \quad 0,05$

tepat guna

$6,11 \quad 0,06$

baru

5 Kesesuaian

4,04

0,04

bahan-bahan

dalam

produksi teh

sepang

6 Komposisi

bahan-

bahannya

7 Cara

pengolahan

bahan

8 Umur

4,72

0,05

tanaman

yang

disyaratkan

dalam

berproduksi

9 Bagian

$4,18 \quad 0,04$

tanaman

yang

disyaratkan

dalam

berproduksi

10 Kesesuaian

$4,57 \quad 0,05$

bahan-bahan

dalam

produksi teh

sepang

11 Komposisi $\quad 9,02 \quad 0,09$

bahan-

bahannya

12 Cara

$4,87 \quad 0,05$

pengolahan

bahan

13 Ukuran yang 4,63 0,05

sesuai dalam

setiap sajian

14 Tempat

produksi

15 Alat-alat

produksi

16 Tenaga kerja
$3,48 \quad 0,04$

$5,29 \quad 0,05$

$3,35 \quad 0,03$ 


\begin{tabular}{rlrl} 
& dalam \\
memproduksi & & \\
17 & $\begin{array}{l}\text { teh sepang' } \\
\text { Pelindung isi } \\
\text { (protection) }\end{array}$ & 7,17 & 0,07 \\
18 & $\begin{array}{l}\text { Image } \\
\text { produk }\end{array}$ & 6,68 & 0,07 \\
19 & $\begin{array}{l}\text { Informasi } \\
\text { Produk } \\
\text { Inovasi } \\
\text { produk }\end{array}$ & 6,94 & 0,07 \\
\hline
\end{tabular}

Dari tabel 10 diatas diperoleh nilai Raw Weight tinggi dari atribut-atribut; produk temasuk teh herbal (harga), komposisi bahanbahannya (aroma), produk termasuk teh herbal, dan perlindungan isi (protection) pada atribut kemasan, keempat sub atribut tersebut yang menjadi prioritas utama untuk ditingkatkan kinerjanya dalam memenuhi kepuasan konsumen teh sepang.

\subsubsection{Tahap penyusunan House Of Quality (HOQ)}

Sebelum penyusunan House Of Quality (HOQ) atau rumah kualitas, selain data-data diatas peneliti memerlukan data penelitian tentang identifikasi variabel teknik yang berhubungan dengan proses produksi teh tepang'. Berikut ini disajikan tabel variabel teknik produksi teh sepang' adalah:

\subsubsection{Variabel Teknis Teh Sepang}

Tabel 11. Variabel teknis dalam proses produksi teh sepang'

\begin{tabular}{cl}
\hline No & \multicolumn{1}{c}{ Variabel proses produksi } \\
\hline 1 & Menyortir bahan baku \\
2 & Menjemur bahan baku kayu sepang \\
3 & Menserut bahan baku menggunakan \\
& ketam \\
4 & Menjemur hasil serutan kayu sepang
\end{tabular}

5 Memanaskan serutan kayu sepang pada suhu 40-50 derajat celsius

6 Mendinginkan hasil serutan selama beberapa menit

7 Memblender bahan baku yang lainnya

8 Mencampur semua bahan baku dalam kantong teh

9 Merekatkan kantong teh

10 Membungkus/ memasukkan dalam kotak teh yang tersedia

\subsubsection{Relationship and Technical Correlation}

Relationship perlu dibuat untuk memetakan hubungan dan ketergantungan antar tim respon teknis dengan kebutuhan konsumen. Dalam menggambarkan hubungan ini pemberian nilai oleh tim pengembang disesuaikan dengan pertalian hubungan antara respon teknis dengan sub atribut produk teh sepang'. nilai ini didasarkan pada tabel 2 . Relationship. 
Tabel 12. Matriks korelasi antara atribut kebutuhan konsumen dengan respon teknis

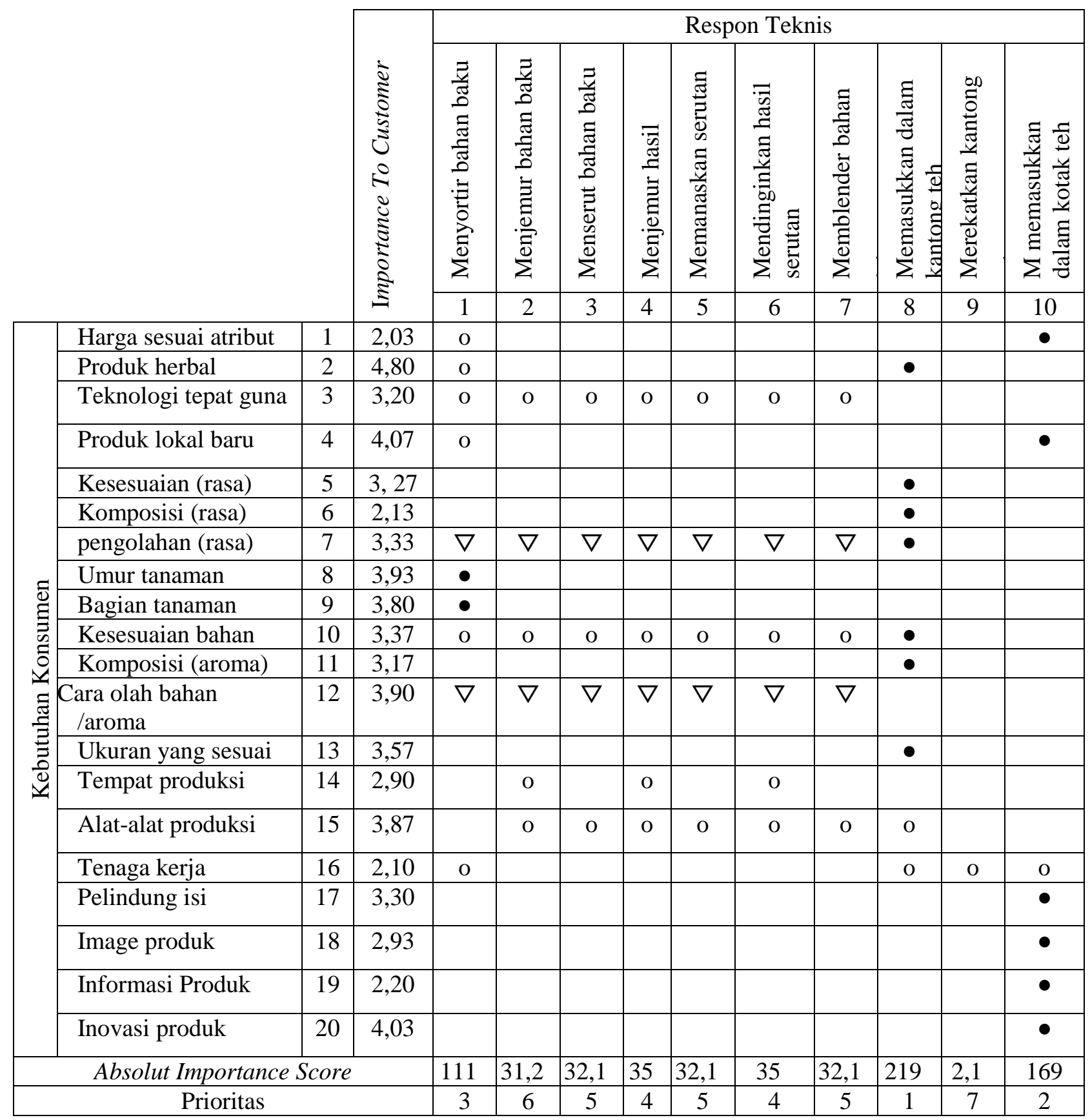


Tabel 13. Matriks korelasi antar respon teknis

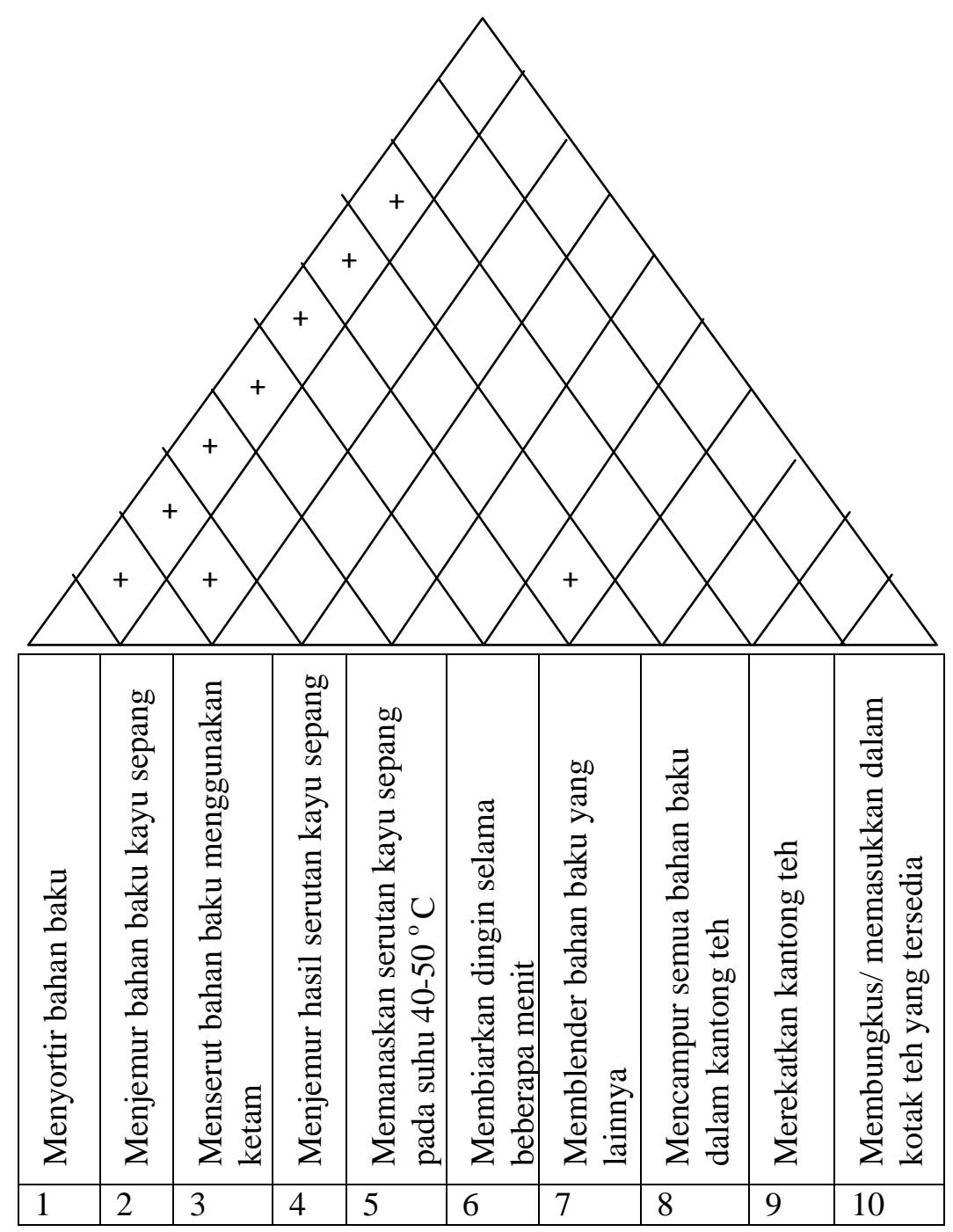


Tabel. 14 Analisis Quality Function

Deployment

\begin{tabular}{|c|c|c|c|c|}
\hline No & Atribut & $\begin{array}{c}\text { Tingkat } \\
\text { Kepuaa } \\
\text { san } \\
\text { Konsum } \\
\text { en Teh } \\
\text { Sepang' }\end{array}$ & $\begin{array}{l}\text { Go } \\
\text { al }\end{array}$ & $\begin{array}{c}\text { Keterang } \\
\text { an }\end{array}$ \\
\hline \multirow[t]{2}{*}{1} & Harga & 2,03 & 3,9 & ditingkatk \\
\hline & $\begin{array}{l}\text { sesuai } \\
\text { dengan } \\
\text { atribut } \\
\text { lainnya }\end{array}$ & & 0 & an \\
\hline \multirow[t]{2}{*}{2} & Produk & 4,17 & 4,8 & ditingkatk \\
\hline & $\begin{array}{l}\text { termas } \\
\text { uk teh } \\
\text { herbal }\end{array}$ & & 0 & an \\
\hline \multirow[t]{2}{*}{3} & Teknol & 3,87 & 3,8 & dipertahan \\
\hline & $\begin{array}{l}\text { ogi } \\
\text { tepat } \\
\text { guna }\end{array}$ & & 7 & kan \\
\hline \multirow[t]{2}{*}{4} & Produk & 4,57 & 4,5 & dipertahan \\
\hline & $\begin{array}{l}\text { lokal } \\
\text { baru }\end{array}$ & & 7 & kan \\
\hline \multirow[t]{2}{*}{5} & Kesesu & 3,57 & 3,6 & ditingkatk \\
\hline & $\begin{array}{l}\text { aian } \\
\text { bahan- } \\
\text { bahan } \\
\text { dalam } \\
\text { produk } \\
\text { si teh } \\
\text { sepang }\end{array}$ & & 7 & an \\
\hline \multirow[t]{2}{*}{6} & Kompo & 1,77 & 4,1 & \\
\hline & $\begin{array}{l}\text { S1S1 } \\
\text { bahan- } \\
\text { bahann } \\
\text { ya }\end{array}$ & & 7 & an \\
\hline \multirow[t]{2}{*}{7} & Cara & 3,40 & 4,1 & ditingkatk \\
\hline & $\begin{array}{l}\text { pengol } \\
\text { ahan } \\
\text { bahan }\end{array}$ & & 7 & an \\
\hline \multirow[t]{2}{*}{8} & Umur & 4,33 & 4,3 & dipertahan \\
\hline & $\begin{array}{l}\text { tanama } \\
\mathrm{n} \text { yang } \\
\text { disyara }\end{array}$ & & 3 & kan \\
\hline
\end{tabular}

tkan

dalam

berpro

duksi

9 Bagian

tanama

n yang

disyara

tkan

dalam

berpro

duksi

$10 \quad$ Kesesu $\quad 3,70 \quad 4,1$ ditingkatk

aian

bahan-

bahan

dalam

produk

si teh

sepang

11 Kompo

sisi

bahan-

bahann

ya

12 Cara

pengol

ahan

bahan

13

Ukur

sesuai

dalam

setiap

sajian

14 Tempa

4,03

4,0 dipertahan

$\mathrm{t}$

produk

$4,17 \quad 4,3 \quad$ ditingkatk

3 an

$4,00 \quad 4,3 \quad$ ditingkatk

3 an

si

15 Alat-

alat

produk

4,0 ditingkatk

0 an

si

16 Tenaga

kerja

dalam
4,0 ditingkatk

0 an 
mempr

oduksi

teh

sepang

17 Pelind ung isi

(protec tion)

$18 \quad$ Image produk

2,63

5,0 ditingkatk

0 an

19

$\begin{array}{lccl}\begin{array}{l}\text { Inform } \\ \text { asi }\end{array} & 1,90 & 5,0 & \text { ditingkatk } \\ \text { Produk } & & 0 & \text { an } \\ \begin{array}{l}\text { Inovasi } \\ \text { produk }\end{array} & 4,43 & 4,0 & \text { dipertahan } \\ & & 0 & \text { kan }\end{array}$

Sebagai akhir dari seluruh tahapan Quality Function Deployment (QFD) dan sebagai kebijakan yang dapat diambil home industry teh sepang', maka beberapa tindakan strategi yang dapat digunakan dalam meningkatkan kinerja kualitas produk lokal teh sepang' antara lain:

- Strategi peningkatan keistimewaan (feature) yang berhubungan dengan desain kemasan yang menarik.

- Home Industry mempertahankan produk teh sepang' sebagai produk lokal baru dan termasuk produk herbal dan juga inovasi produk baru dengan menciptakan jaringan pemasaran dengan semua pihak dalam rantai distribusinya.

- Strategi peningkatan kualitas rasa, aroma dan warna teh sepang' dapat lakukan dengan meningkatkan kualitas bahan baku produk, serta pengijian olganoleftik.

- Peningkatan atribut kebersihan dengan memperhatikan kebersihan tempat dan alat- alat dalam berproduksi serta menerapkan K3 pada tenaga kerja.

Target respon teknis untuk produk teh sepang' yang dikembangkan adalah sebagai berikut:

Tabel 15. target respon teknis dari produk teh

\begin{tabular}{|c|c|}
\hline Respon Teknis & $\begin{array}{c}\text { Target Kinerja Respon } \\
\text { Teknis }\end{array}$ \\
\hline $\begin{array}{l}\text { Menyortir } \\
\text { bahan baku }\end{array}$ & $\begin{array}{l}\text { Bahan baku yang dipilih } \\
\text { harus bagian dalam kayu } \\
\text { secang yang berwarna merah }\end{array}$ \\
\hline $\begin{array}{l}\text { Menjemur } \\
\text { bahan baku } \\
\text { kayu sepang }\end{array}$ & $\begin{array}{l}\text { Menjemur bagian bahan } \\
\text { baku yang sudah di sortir } \\
\text { dibawah terik matahari } \\
\text { langsung untuk mengurangi } \\
\text { getah pada pada kayu } \\
\text { secang. }\end{array}$ \\
\hline
\end{tabular}

Menserut Menggunakan ketam listrik bahan baku agar hasil serutan lebih halus menggunakan ketam listrik

Menjemur hasil Menjemur hasil serutan kayu serutan kayu secang dibawah terik sepang matahari langsung serta harus menggunakan wadah yang bebas dari kontaminasi debu.

Memanaskan Memakai suhu $40-50^{\circ} \mathrm{C}$ agar serutan kayu kayu secang tidak bergetah sepang pada serta benar-benar kering. suhu $40-50{ }^{\circ} \mathrm{C}$

Membiarkan Membiarkan dingin hasil dingin selama pemanasan agar mudah beberapa menit untuk dihancurkan menjadi serutan-serutan kecil yang siap dicampurkan dengan bahan-bahan lainnya.

Memblender Memblender bahan baku bahan baku satu persatu hingga 


\begin{tabular}{llr} 
yang lainnya & \multicolumn{2}{l}{ dihasilkan bahan-bahan yang } \\
sangat halus \\
Mencampur & $\begin{array}{l}\text { Menggunakan alat-alat yang } \\
\text { semua bahan } \\
\text { baku dalam }\end{array}$ & $\begin{array}{l}\text { higienis dalam proses } \\
\text { pencampuran dan }\end{array}$ \\
kantong teh & $\begin{array}{l}\text { pengadukannya agar tidak } \\
\text { terkontaminasi bakteri. }\end{array}$ \\
Merekatkan & $\begin{array}{l}\text { Menggunakan alat-alat yang } \\
\text { bisa merekatkan dengan baik }\end{array}$ \\
kantong teh & $\begin{array}{l}\text { agar kantong teh tidak } \\
\text { terbuka saat pengemasan. }\end{array}$ \\
Membungkus/ & $\begin{array}{l}\text { Mengatur jumlah dan posisi } \\
\text { memasukkan }\end{array}$ & yang tepat agar tersusun rapi \\
dalam kotak & $\begin{array}{l}\text { dan menggunakan } \\
\text { teh yang }\end{array}$ & $\begin{array}{l}\text { alumunium foil dalam } \\
\text { pengemasan. }\end{array}$ \\
tersedia & pengem \\
\hline
\end{tabular}

\section{KESIMPULAN DAN SARAN}

\subsection{Kesimpulan}

Berdasarkan hasil yang dicapai dalam penelitian ini maka dapat disimpulkan sebagai berikut:

1. Dari hasil analisis Importance To Customer atas produk teh sepang' menunjukkan bahwa dari 20 sub atribut terdapat 10 kepentingan yang menjadi prioritas pertama dalam pemenuhan kepuasan pelanggan teh sepang antara lain secara berturut-turut yang menjadi prioritas konsumen dalam peningkatan kualitas produk antara lain: 1) Harga sesuai dengan atribut lainnya (harga), 2) Tenaga kerja dalam memproduksi teh sepang'(kebersihan), 3) Komposisi bahanbahannya (rasa), 4) Informasi Produk (kemasan), 5) Tempat produksi (kebersihan), 6) Image produk (kemasan), 7) Komposisi bahan-bahannya (aroma), 8) Teknologi tepat guna (harga), 9) Kesesuaian bahan-bahan dalam produksi teh sepang (rasa), 10) Pelindung isi (protection) (kemasan), sedangkan 10 kepentingan berikutnya adalah 11) Cara pengolahan bahan, 12) Kesesuaian bahan-bahan dalam produksi teh sepang, 13) Ukuran yang sesuai dalam setiap sajian, 14) Bagian tanaman yang disyaratkan dalam berproduksi, 15) Alat-alat produksi, 16) Cara pengolahan bahan, 17) Inovasi produk, 18) Produk lokal baru, 19) Produk termasuk teh herbal 20) Umur tanaman yang disyaratkan dalam berproduksi.

2. Dari analisis relationship yang digambarkan pada house of quality diantara sepuluh variabel teknik produksi ada tiga variabel teknis produksi yang sangat berpengaruh terhadap peningkatan kualitas produk teh sepang' antara lain: Mencampur semua bahan baku dalam kantong teh, Membungkus/ memasukkan dalam kotak teh yang tersedia, Menyortir bahan baku.

3. Berdasarkan analisis tingkat kepuasan konsumen (customer satisfaction performance) menunjukkan bahwa terdapat tiga sub atribut yang menjadi nilai kepuasan konsumen produk teh sepang' bila dibandingkan dengan teh sariwangi adalah pertama sub atribut produk termasuk teh herbal dengan tingkat kepuasan konsumen sebesar 4, 17, kedua sub atribut produk lokal baru dengan tingkat kepuasan konsumen sebesar 4,57, dan ketiga sub atribut teknologi tepat guna dengan tingkat kepuasan konsumen sebesar 3,87. Dari keempat sub atribut tersebut menunjukkan bahwa ada respon positif terhadap keberadaan produk teh sepang' sampai saat ini. 


\subsection{Saran}

1. Dalam melakukan usaha pengembangan maupun peningkatan kualitas produk teh sepang', pihak produsen teh sepang' sebaiknya memulainya dari atribut-atribut yang sangat dipentingkan oleh konsumen.

2. Dalam proses produksi teh sepang' sebaiknya produsen menentukan komposisi bahan tertentu yang sebelumnya telah dilakukan pengujian olganoleptik agar rasa maupun aroma teh sepang' dapat seimbang.

3. Perlu adanya peningkatan kinerja kualitas pada atribut-atribut teh sepang' yang masih belum bisa memuaskan konsumen ataupun pelanggan, dengan berbagai teknik-teknik tertentu. Sehingga diharapkan kedepannya produk teh sepang' akan menjadi salah satu produk lokal yang diperhitungkan.

\section{DAFTAR PUSTAKA}

Balakrishnan, J. Robertson, B. Stolee, J. dan Karim, S. 2010. Applying QFD In Food Safety Management. British Food Journal. 112 (6) :624-639.

Codney; E. Elrod, C.C. dan Uppalanchi, A. 2012. Analyzing Customer Requirements for the American Society of Engineering Management Using Quality Function Deployment. Engineering Management Journal. 24 (1): 47-57.

Cohen, L. 2007. Quality Function Deployment: How To Make QFD Work For You. Addison-Wesley. Amerika.

Kumala, S. dan Muhamad, G. 2008. Isolasi dan Penapisan Kapang Endofit Tanaman Secang (Caesalpinia Sappan L) Sebagai Penghasil Senyawa Antibakteri. Medicinus. 21 (2): 12-14.
Munawaroh, S. 2014. Wedang Uwuh Sebagai Ikon Kuliner Khas Imogiri Bantul. Jurnal Jentra. 9 (1): 69-79. 